\title{
The Impact of Group Cohesiveness on Organizational Performance: The Nigerian Case
}

\author{
Adeleke O. Banwo ${ }^{1}$, Jianguo $\mathrm{Du}^{1} \&$ Uchechi Onokala ${ }^{2}$ \\ ${ }^{1}$ School of Management, Jiangsu University, China \\ ${ }^{2}$ Department of Business Administration, University of Lagos, Nigeria \\ Correspondence: Adeleke O. Banwo, School of Management, Jiangsu University, 301, Xuefu Road, Zhenjiang, \\ Jiangsu Province, China. E-mail: lekebanwo@gmail.com
}

Received: January 19, 2015

Accepted: May 7, 2015

Online Published: May 22, 2015

doi:10.5539/ijbm.v10n6p146

URL: http://dx.doi.org/10.5539/ijbm.v10n6p146

\begin{abstract}
Several scholarly studies have associated strong group performance with a high level of group cohesion among the members. In this study, we investigated the impact of group cohesion on organizational performance using Carron, Widmeyer, and Brawley group environment questionnaire and Beauchamp, Bray and Carron (2002) role perception and acceptance scale administered to 180 employees in four branches of a commercial bank in Nigeria. The questionnaire was divided into three sections: demographics, role perception, acceptance and group cohesion. Our finding was inconclusive because group cohesion was found to be strong in groups with good performance likewise groups with weak performance. Further examination showed that groups with high cohesion consisting of members with higher organizational tenure outperformed groups made up of employees with lower organizational tenure.
\end{abstract}

Keywords: groups, group cohesion, Nigeria, role perception, performance

\section{Introduction}

Groups abound in virtually all human settings and their formation takes different dimensions in relation to the interplay of several factors in their environment. Group Dynamics and its construct, group cohesion have continually enjoyed the attention of scholars in all disciplines (Greer, 2012) due to the universality of groups and the interplay of behavioral variants and dynamics prevalent in groups. The context of group cohesion remains broad and scholars have continued to propose varied definitions and conceptual framework for group cohesion studies (Cota, Evans, Dion, Kilik, \& Longman, 1995; Mudrack, 1989a, 1989b). The group cohesionperformance relationship continuum has been broadly investigated and findings by researchers have shown varied outcomes on the nature of their relationship mainly due to different moderating variables, sample size, contexts, and other yardstick used. While early studies did not present a methodical linkage between performance and cohesion (Stogdill, 1972), Evans and Dion $(1991,2012)$ in their meta-analytic studies posited the effect of cohesion-performance to be more positive and stronger in smaller groups than larger groups. Mullen and Copper (1994) meta-analysis also confirmed the positive relationship. Conversely, other studies presented divergent views by moderating variables such as group size, study design, settings, level of analysis, task interdependency, goal acceptance, methodology and group norm (Castaño, Watts, \& Tekleab, 2013; Dobersek, Gershgoren, Becker, \& Tenenbaum, 2014; Gully, Devine, \& Whitney, 1995; Langfred, 2000; Levine \& Moreland, 1990).

The complexity in group cohesiveness is inherent in the difficulty in measuring this construct, the methodologies and variables investigated in group cohesion and performance literature (Cota et al., 1995; Mudrack, 1989a, 1989b). Retrospectively understanding the nature of group dynamics provides a fundamental premise for exploring the evolving nature and broad framework of group cohesion. An in-depth appraisal of group dynamics analogy can be traced to the pioneer and foundational works of Kurt Lewin, who coined the term 'group dynamics' and Tuckman's group development theory, while the latter summarizes group development process into five stages, namely forming, storming, norming, performing and adjourning stages, the former provides the basic framework of how complex social processes impact members in a group. The stage and life-cycle of groups have a positive or negative correlation with the prevalent form of group cohesion and this must always be taken into cognizance in evaluating the outcomes of group cohesion and performance. For example, the nature 
and dimension of group cohesiveness in a group still at its storming stage will definitely be different from a similar group at its performing stage due to inherent uniqueness of the stages and their operational contexts. These stages are continually influenced by the nature of group dynamics arising from interplay of social, structural and task elements. For the purpose of this paper, we adopt some of the most widely used definitions for cohesion, starting with Festinger, Schachter, and Back (1950) classical definition of cohesion which asserts it "as the total field of forces acting on individuals to remain in the group". The total field of forces aptly connotes the totality of exogenous, endogenous variables and elements that are within and outside the group control. Secondly, group cohesion also depicts "a broad and dynamic process which is reflected in the tendency for a group to stick, bond together and remain united in the pursuit of its goals and institutional objectives" (Carron, Brawley, \& Widmeyer, 1998). Carron and Brawley $(2000,2012)$ in their "cohesion conceptual and measurement studies" suggested the necessity of evaluating and taking cognizance of the structure and context of groups in providing an operational definition for group cohesion. This study intent was to investigate whether Group Cohesion has impacts on organizational performance within the Nigerian context by examining the interplay of demographics, role perception, acceptance and group cohesion-performance continuum with the aim of contributing further evidence to the group cohesion studies.

\section{Literature Review}

The volume of research, lack of integration, inconsistency in measurements and the conceptualization of group cohesion can be traced to the milieu of process variables and parameters used and this dilemma can be resolved through a systematic approach to the evaluation of parameters used (Drescher, Burlingame, \& Fuhriman,2012). The dimensionality of cohesion as a one-dimensional or multidimensional construct sheds light on its evolution, differences in outcomes and methodology of these schools of thoughts. Proponents of the one-dimensional model (Hogg, 1992; Lewin, 1935; Lott \& Lott, 1965) use distinct parameters in studying the construct and focus more on the individual than the group, using narrow and non-standardized definitions. The deficiencies and narrow framework of the one-dimensional model resulted in the emergence of multidimensional school of thought. They adopted a rather robust approach asserting that a myriad of factors and variables exert varying influences on cohesion in groups and often lead to diverse outcomes (Ariely, 2014; Carron, Widmeyer, \& Brawley, 1985; Dion, 2000).

A major hallmark of the multidimensional model lies in its adoption of the task-social group perspective and elements (members)-system (group) group perspective as fundamental to understanding the varied nature of cohesion in diverse group settings and time. Though research findings of the two schools of thought have continued to present conflicting outcomes, yet the robustness of the multidimensional process is relevant to our study. Burlingame, Fuhriman, and Drescher (1984) study 'scientific inquiry into small group process a multidimensional approach' provides four insightful dimensions on the 'who, what, how and when' of group process and posits that a critical analysis of the interplay of these variables and elements provides signposts to explain and justify reasons for the divergence in outcomes of cohesion research in small groups. A key and fundamental participant for observation in most groups is the person as depicted by the 'Who'; the makeup and configuration of the person represents an embodiment or personification of an individual made up of a myriad of forces ranging from cultural, social, technological, environmental and external forces that have molded and influence his personality at different points in time. For instance, two groups with the same number of members may perform differently due to several factors and even the level of cohesion among members in groups varies at different levels, situations and roles, also the network of dyads and triads in which the person engages has positive or negative correlation with cohesion.

The field of forces that influences a person to remain in a group draws inferences from Maslow's (1943) need theory ,since members of the group have varied needs, personality, pre-conceived perceptions ,experience affiliation needs (McClelland, 1961) and motivations. The 'what' dimension embodies the totality and complexity of process and response variables being studied, it becomes obvious that variables been investigated in cohesion studies varies and also a major factor contributing to the divergence in outcomes and methodology. Third the 'how' dimension determines how the process variables is being measured and how the method used has a direct effect on results and findings. In addition the 'when' dimension refers to the time when the process variables are studied and investigated, the timing of occurrences and investigations in research influences the outcomes in group processes. Time and timing horizons must be taken into consideration in evaluating cohesion studies, controlling and moderating of variables. Its effect is evident in the distinct nature and group dynamics that exists at different levels of a group life cycle and development. 


\subsection{Group Cohesion and Performance}

Performance remains the most widely studied variable in the group cohesion literature and researchers have continually explored the cohesion-performance continuum due to its complexity and relevance to group studies (Mullen \& Cooper, 1994).Studies on the two constructs has been examined within groups at different levels and the plethora of meta-analyses conducted on their relationship reinforces the growing attention enjoyed (Chiocchio, \& Essiembre, 2009; Evans \& Dion, 1991; Gully, Devine \& Whitney, 2012; Mullen \& Cooper, 1994; Pescosolido \& Saavedra, 2012; Wise, 2014). The divergence in outcomes in these meta-analysis and research reinforces the complexity of these constructs and time dimension effect on the findings (Levine \& Mooreland, 1990). The debate on which impacts the others suggest that performance leads to cohesion (Mullen \& Cooper, 1994) and group cohesion leads to performance (Chang \& Bordia, 2001). Components of cohesion had different levels of effect and correlation between performance and cohesion (Beal, Cohen, Burke, \& McLendon, 2003). The nature of cohesiveness in a group is a reflection of the level of communication and bonding among group members and results in task, role commitment, group pride and interpersonal attraction (Rosh, Offermann, \& Van, 2012; Shaw, 1981).

Group pride plays a positive role in situations where the relationship between performance and cohesion are positive and often dependent on success in past performances (Rosh et al., 2012). Overall, the relationship between cohesion and performance has been found to be positive in some studies and negative in other studies, this seeming contradiction confirms the complexity of research in group cohesion (Hornaday, 2014). Mullen and Copper (1994) experimental and associational method are relevant in investigating the nature of the relationship between cohesiveness and performance, the former suggests the creation of high and low level group cohesiveness to examine the effect each type would have on group performance and the latter requires an in-depth appraisal of the group's opinion of cohesion with both methods leading to different outcomes. Chiocchio and Essiembre (2009) meta-analysis of cohesion and performance used group type and settings (context) as moderating variables to distinguish the cohesion-performance correlations. The two moderators identified 33 group cohesion-performance association, they also contrasted cohesion and performance in project and work groups from the perspective of effects and behavioral measure of performance and discovered that cohesion-performance correlation was stronger and higher in project teams for behavioral measures and stronger in work teams for outcome measures.

\subsection{Group Cohesion: The Timing Effect}

Burlingame et al., (1984)study on time dimension highlighted the importance of examining time horizon and dimensions in cohesion studies. The timing of the various analyses in group cohesion research has continually contributed to the contradictory results. Mulvey and Klein (1998) examined the influence of social perception on group processes and performance in two projects over an 8 week time frame and the outcome of their findings confirmed that group goals have a strong correlation to group performance. Greene (1989) investigated the relationship between group cohesion and performance and affirmed the existence of a common association between the constructs. Chang and Bordia (2001) also examined group cohesion and group performance, relationship between tasks and social cohesion at the group level and effect of longitudinal changes over 5 weeks and posits that performance-cohesion relationship is stronger than cohesion-performance linkage using Time 1 and Time 2 with group cohesion construed as an antecedent and not a consequence of group performance and different time frames used in most studies has not yielded conclusive results. Taylor, Doria and Tyler (1983) observed that poor performance by the group can have a negative impact on cohesion which is dependent upon the attribution of the group.

\subsection{Cohesiveness and Group Size}

Groups exist in different forms and the size of a group is often a function of the mission and vision for creating and joining the group, their size varies in dyads and triad with multiple spatial aggregations (Forsyth, 2009). Studies have involved groups with varying sizes and human elements with distinct behaviors, perceptions and motives. The fusion of individual behaviors of members and leadership of groups determines the nature of cohesiveness and forces compelling members to remain in the group. The effect of size in group dynamics varies from small to big groups, closely knitted groups to loosely knit groups and while it should be easier to manage small groups, the dynamics of large groups presents an array of in-group and out-group dynamics (Ratner, Dotsch, Wigboldus, Knippenberg, \& Amodio, 2014) resulting in the emergence of different level cohesiveness and sub-groups that are pursuing different objective. Gooding and Wagner (1985) meta-analysis on size-performance relationship indicates that there is a sharp difference in relations between subunit size and performance, organizational size and performance and concluded that organizational size does not translate to 
economies of scale.

Carron and Spink (1995) examination of the relationship between cohesion and group size using four studies posited that smaller groups had a greater level of task and social cohesion than big groups. Evaluating the impact of size on cohesion in different settings and contexts results in divergent outcomes, this variable is critical and one of the most influential variable in determining the structure and motivation levels in groups. The presumption that cohesion is presumed to decrease as the size of a group increases in sport (Widmeyer, Lawrence, \& Carron, 1990) could apply to other fields. This may be an indicator of the emergence of diverse group problems like loafing, polarization and group think in the group. Managing the social networks, linkages and sociometry in small groups is easier compared to bigger groups where several factors and variable interplay to determine the level of cohesiveness in different types of groups.

\section{Methods}

Data for this study was obtained using a questionnaire administered to employees in four branches of a commercial bank in Nigeria. Beauchamp's et al (2002) role perception scale was used to measure types of perceived ambiguity experienced by the employees, the scale comprises of 40 items with 5 -item sub -scales to measure the four types of perceived ambiguity. Role satisfaction and acceptance was measured using Bray (1998) measure model, the model lays emphasis on differentiating the relationship of two fundamental constructs; role acceptance and role satisfaction and their impact on group cohesiveness. It comprises of a set of ten questions aimed at evaluating employees feelings with regards to their roles and responsibilities in their groups and teams using a 10-point Likert scale with ranges from 'not at all' at the lowest rung and 'totally' at the highest rung. The higher the score the higher the level of role acceptance and satisfaction of the members.

In addition, group cohesion was determined using Carron, Widmeyer, and Brawley (1985) Group Environment Questionnaire (GEQ) to measure individual employees of the group as a whole unit and their personal attractions to the group. The questionnaire was divided into three sections: demographics, role perception, acceptance and group cohesion and was administered to a total of 180 employees from 18 marketing team with a total of 109 questionnaires returned fully completed, representing a response rate of $60.5 \% .56 \%$ of the respondents were male, while $44 \%$ were female. An analysis of the educational qualifications of the respondents shows that $49 \%$ of the respondents had only Bachelor's degrees or Higher National Diploma (HND) while 43\% had a Masters of Business Administration (MBA) or Master's Degree. The average length of service with the bank for all the respondents was 5.98 years. A greater part of the respondents $(53.2 \%)$ had spent between $1-5$ years at the bank while $12.8 \%$ of the respondents had spent between $11-15$ years at the bank.

\section{Analysis and Results}

\subsection{Findings on Role Perception and Acceptance}

An individual is more likely to work harder if he/she is happy with his/her assigned role in the group. The first hypothesis in this section test the validity of the assumption that an individual is more likely to work hard if he/she is happy with his/her assigned role.

\section{H01: I do not enjoy performing the responsibilities assigned to me}

HA1: I enjoy performing the responsibilities assigned to me

Using the p-value (0.000) obtained from the one-sample t-test; the null hypothesis is rejected. This implies that the respondents enjoy performing the responsibilities assigned to them. Further analysis was conducted to understand if length of service with the bank played any role in role acceptance. It was observed that the mean value on role acceptance increases as the number of years spent in the bank increases. Employees who had spent between 11 to 15 years have the highest mean of 4.36 with a standard deviation of 0.497 , while employees who have spent between 1 to 5 years have the lowest mean of 2.60 with a standard deviation of 1.337. Another factor that was tested was the willingness of the team members to perform responsibilities beyond their assigned roles to ensure the group's success. The hypothesis seeks to test the assumption that a strong team spirit is evident when team members are willing to take on additional responsibilities to ensure the success of the team.

H02: I do not go beyond my assigned responsibilities.

HA2: I usually go beyond my assigned responsibilities to ensure the success of my team. The p-value obtained from the one-sample t-test on team spirit is 0.000 . Therefore, the null hypothesis is rejected. This implies that if a team member believes strongly in his/ her team, the team member is usually willing to go beyond his/her assigned responsibilities in order to ensure the success of the team. 
Table 1. One-Sample T-test on role acceptance and team spirit

\begin{tabular}{|c|c|c|c|c|c|c|}
\hline & \multicolumn{6}{|c|}{ Test Value $=0.05$} \\
\hline & \multirow[b]{2}{*}{$\mathrm{T}$} & \multirow[b]{2}{*}{ df } & \multirow[b]{2}{*}{ Sig. } & \multirow[b]{2}{*}{ Mean Difference } & \multicolumn{2}{|c|}{$\begin{array}{c}95 \% \text { Confidence Interval of the } \\
\text { Difference }\end{array}$} \\
\hline & & & & & Lower & Upper \\
\hline Role Acceptance & 25.539 & 108 & .000 & 3.225 & 2.97 & 3.48 \\
\hline Team Spirit & 30.996 & 108 & .000 & 3.418 & 3.20 & 3.64 \\
\hline Information Sharing & 30.769 & 112 & .000 & 3.366 & 3.15 & 3.58 \\
\hline Shared values & 25.539 & 108 & .000 & 3.225 & 2.97 & 3.48 \\
\hline
\end{tabular}

\subsection{Findings on Group Cohesion}

Group Cohesion was measured using three values: shared values, information flow and willingness to leave the team.

For group cohesion to exist, it is assumed that members of the team must largely share the same values. A one-sample t-test was carried out to test this assumption.

H03: A group member does not share all the values of the team.

HA3: A group member shares all the values of the team.

The test results indicated that group members shared the values of the team. A negative relationship was observed between shared values and turnover intentions amongst team members using simple regression analysis. This indicates that if a team member believes strongly in his team, he/she is more likely to share the same values with his/her team members.

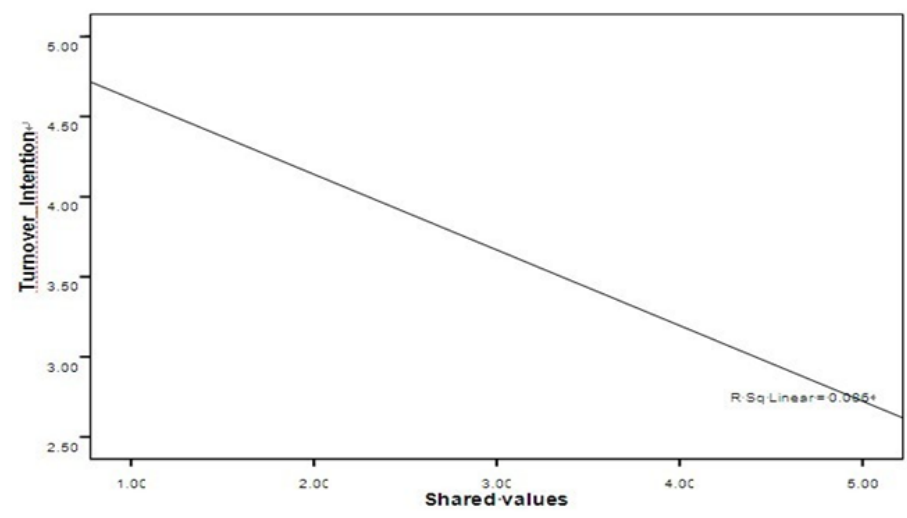

Figure 1. The relationship between shared values and team turnover intention

Another key assumption of a very cohesive team is that members share information freely with their team members. This helps to increase team member's productivity as members have access to all the necessary resources needed to succeed. The one-sample t-test used to test this assumption indicated that team members share information freely with other members of their team. In order to corroborate our hypotheses on group cohesion, a question was asked on intention to leave their present group-turnover intention.

Out of the 109 responses received for this question, 17 respondents indicated their interest in leaving their current teams while 7 respondents were indifferent to staying or leaving their current teams. Indifference to staying or leaving their current team may be interpreted as having a weak connection to their current team; therefore, these indifferent respondents were grouped along with members who expressed their interest to leave their present teams. $77.98 \%$ of the respondents indicated their interest in remaining in their current team. The simple regression analysis plot between team turnover intention and team identity shows that team identity has a negative association with turnover intentions. A team member who identifies highly with his team is less likely to quit the team. 


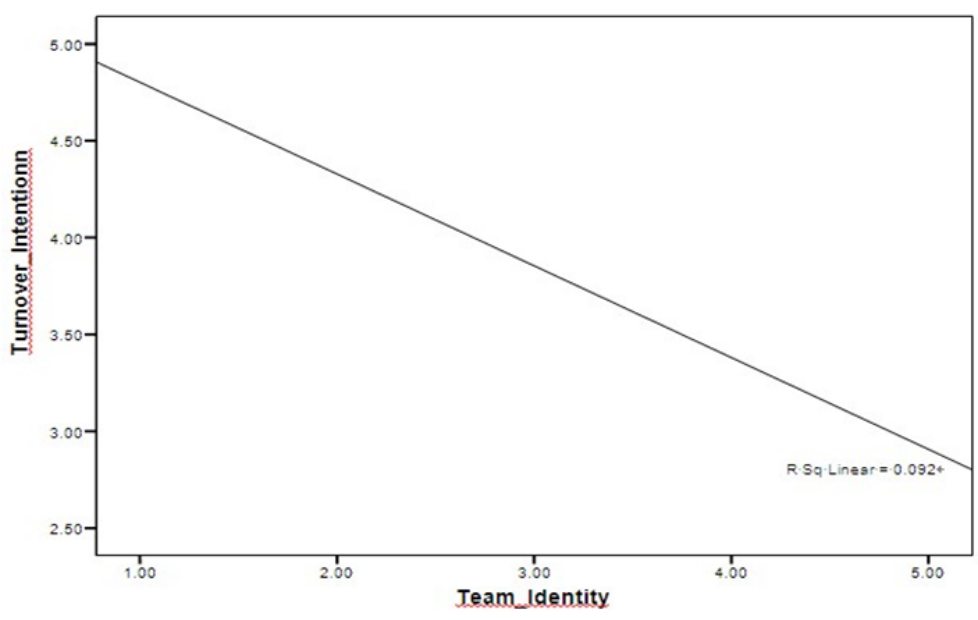

Figure 2. Relationship between team identity and team turnover intention

\subsection{Findings on Team Performance}

In line with enhancing the empirical and theoretical attention to the group cohesion dynamics in different strata of groups (Chiocchio \& Essiembre, 2009; Greer, 2012) and though many studies have linked strong team performance with high level of cohesion among the team members. The finding from this study was inconclusive because group cohesion was found to be strong in teams with good performance as well as teams with weak performance. Further analysis showed that a negative association exists between organizational tenure and team performance.

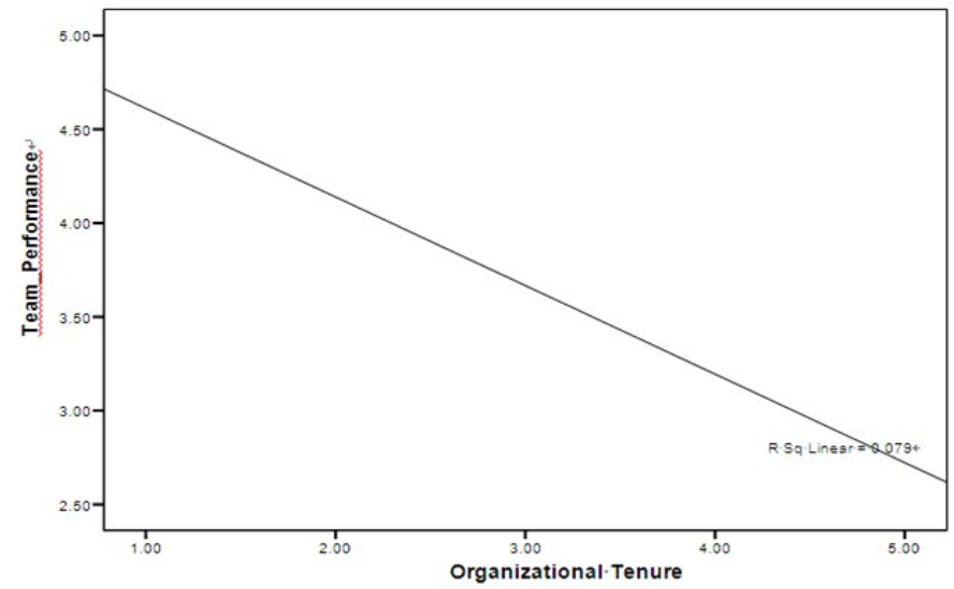

Figure 3. Relationship between organizational tenure and team performance

This means that teams with employees who had spent more years working for the organization showed better performance when compared with teams made up of employees with shorter organizational tenure.

\section{Discussions}

Nigeria with its estimated population of 165 million presents one of the attractive investment opportunities for multinationals looking to open new markets. Since its return to civil rule in 1999 after over 20 years of military rule, Nigeria has removed various barriers in order to encourage foreign investment in its economy. The government initiative to attract foreign investment has recorded some success by attracting multinationals mainly from South Africa, India, China and the United States to open offices in Nigeria. While these multinationals seek to transfer their organizational culture of their home country to Nigeria, it is equally imperative for them to understand the Nigerian work culture. The Nigerian workforce presents a new set of challenges to these multinationals because Nigeria has over 250 ethnic groups with distinct work and cultural ethics. Working in 
groups is not a foreign concept to the Nigerian workforce. As multinationals grasp with the various challenges in growing their business in a developing country like Nigeria and managing their Nigerian multicultural work force, it is important to identify the factors that impact the success of work groups and the organization. Group cohesion was observed to be very high amongst the team members observed in this study. However, findings from this study were inconclusive because group cohesion was found to be strong in teams with good performance as well as teams with weak performance. It was observed that teams with high cohesion and members who had higher organizational tenure outperformed teams made up of employees with shorter organizational tenure. This finding presents a major opportunity for organizations operating in Nigeria to depart from the current norm where older employees are not considered valuable.

In most of the layoffs by government offices and private companies in Nigeria, majority of the affected employees are usually employees with long tenure. Organizations need to take various initiatives to motivate employees with long tenure in order to increase the performance of their workforce. Research shows that intrinsic compensation is also an important part of one's compensation package. This is important for organizations operating on a tight budget in a developing country. Programs can be set up to recognize employees with long tenure who are still making a valuable contribution to the organization's success. In addition, organizations can benefit from the wealth of experience of these long tenure employees by setting up formal mentorship programs with the organization. This will ensure that newly hired employees benefit from the experience of these long tenure employees. The scope of this research covered mainly four branches of a financial organization and the results are reflective of the contextual dimension and the setting. A major limitation of this study was the influence of the environmental context, variables measured and timing which makes the results not generalizable. Future researchers should include more variables and conduct cross-country study in similar settings to investigate the effect of context on the findings.

\section{Acknowledgements}

The authors are indebted to anonymous reviewers for their very insightful comments and constructive suggestions, which help ameliorate the quality of this paper. This work is supported by the National Research Foundation of Korea Grant funded by the Korean Government (NRF-2014S1A2A2027622), and supported in part by the National Natural Science Foundation of China under grants 71471076, 71171099, and 71201071 and by the Joint Research of The NSFC-NRF Scientific Cooperation Program under grant 71411170250. This work was also sponsored by Qing Lan Project and 333 Project of Jiangsu Province, and Jiangsu University Top Talents Training Project.

\section{References}

Ariely, G. (2014). Does Diversity Erode Social Cohesion? Conceptual and Methodological Issues. Political Studies, 62(3), 573-595. http://dx.doi.org/10.1111/1467-9248.12068

Beal, D. J., Cohen, R. R., Burke, M. J., \& McLendon, C. L. (2003). Cohesion and performance in groups: a meta-analytic clarification of construct relations. Journal of Applied Psychology, 88, 989-1004. http://dx.doi.org/10.1037/0021-9010.88.6.989

Beauchamp, M. R., Bray, S. R., Eys, M. A., \& Carron, A. V. (2002). Role ambiguity, role efficacy, and role performance: Multidimensional and mediational relationships within interdependent sport teams. Group Dynamics: Theory, Research, and Practice, 6(3), 229. http://dx.doi.org/10.1037//1089-2699.6.3.229

Bray, S. R. (1998). Role efficacy within interdependent teams, measurement development and tests of theory.

Burlingame, G., Fuhriman, A., \& Drescher, S. (1984). Scientific Inquiry Into Small Group Process A Multidimensional Approach. Small Group Research, 15(4), 441-470. http://dx.doi.org/10.1177/104649648401500402

Carron, A. V., \& Brawley, L. R. (2000). Cohesion: conceptual and measurement issues. Small Group Research, 31, 89-106. http://dx.doi.org/10.1177/104649640003100105

Carron, A. V., \& Brawley, L. R. (2012). Cohesion Conceptual and Measurement Issues. Small Group Research, 43(6), 726-743. http://dx.doi.org/10.1177/1046496412468072

Carron, A. V., \& Spink, K. S. (1995). The group size-cohesion relationship in minimal groups. Small Group Research, 26(1), 86-105. http://dx.doi.org/10.1177/1046496495261005

Carron, A. V., Brawley, L. R., \& Widmeyer, W. N. (1998). The measurement of cohesiveness in sport groups. Advances in Sport and Exercise Psychology Measurement, 213-226.

Carron, A. V., Widmeyer, W. N., \& Brawley, L. R. (1985). The development of an instrument to assess cohesion 
in sport teams: the Group Environment Questionnaire. Journal of Sport Psychology, 7, 244-266.

Castaño, N., Watts, T., \& Tekleab, A. G. (2013). A reexamination of the cohesion-performance relationship meta-analyses: A comprehensive approach. Group Dynamics: Theory, Research, and Practice, 17(4), 207. http://dx.doi.org/10.1037/a0034142

Chang, A., \& Bordia, P. (2001). A multidimensional approach to the group cohesion-group performance relationship. Small Group Research, 32, 379-405. http://dx.doi.org/10.1177/104649640103200401

Chiocchio, F., \& Essiembre, H. (2009). Cohesion and performance: A meta-analytic review of disparities between project teams, production teams, and service teams. Small Group Research. http://dx.doi.org/10.1177/1046496409335103

Cota, A. A., Evans, C. R., Dion, K. L., Kilik, L., \& Longman, R. S. (1995). The structure of group cohesion. Personality and Social Psychology Bulletin, 21, 572-580. http://dx.doi.org/10.1177/0146167295216003

Dion, K. L. (2000). Group cohesion: From "field of forces" to multidimensional construct. Group Dynamics: Theory, Research, and Practice, 4(1), 7. http://dx.doi.org/10.1037//1089-2699.4.1.7

Dobersek, U., Gershgoren, L., Becker, B., \& Tenenbaum, G. (2014). The cohesion-performance relationship in sport: A 10-year retrospective meta-analysis. Sport Sciences for Health, 10(3), 165-177. http://dx.doi.org/10.1007/s11332-014-0188-7

Drescher, S., Burlingame, G., \& Fuhriman, A. (2012). Cohesion an odyssey in empirical understanding. Small Group Research, 43(6), 662-689. http://dx.doi.org/10.1177/1046496412468073

Evans, C. R., \& Dion, K. L. (1991). Group cohesion and performance: A meta-analysis. Small Group Research, 22, 175-186. http://dx.doi.org/10.1177/1046496491222002

Evans, C. R., \& Dion, K. L. (2012). Group cohesion and performance a meta-analysis. Small Group Research, 43(6), 690-701. http://dx.doi.org/10.1177/1046496412468074

Festinger, L., Schachter, S., \& Back, K. (1950). Social pressures in informal groups: A study of human factors in housing. New York: Harper \& Brothers.

Forsyth, D. (2009). Group dynamics. Cengage Learning.

Friedkin, N. E. (2004). Social cohesion. Annual Review of Sociology, 30, 409-425. http://dx.doi.org/10.1146/annurev.soc.30.012703.110625

Gooding, R. Z., \& Wagner III, J. A. (1985). A meta-analytic review of the relationship between size and performance: The productivity and efficiency of organizations and their subunits. Administrative Science Quarterly, 462-481. http://dx.doi.org/10.2307/2392692

Greene, C. N. (1989). Cohesion and productivity in work groups. Small Group Behavior, 20, 70-86. http://dx.doi.org/10.1177/104649648902000106

Greer, L. L. (2012). Group Cohesion Then and Now. Small Group Research, 43(6), 655-661. http://dx.doi.org/10.1177/1046496412461532

Gully, S. M., Devine, D. J., \& Whitney, D. J. (1995). A meta-analysis of cohesion and performance: effects of level of analysis and task interdependence. Small Group Research, 26, 497-520. http://dx.doi.org/10.1177/1046496495264003

Gully, S. M., Devine, D. J., \& Whitney, D. J. (2012). A meta-analysis of cohesion and performance effects of level of analysis and task interdependence. Small Group Research, 43(6), 702-725. http://dx.doi.org/10.1177/1046496412468069

Hogg, M. A. (1992). Hogg, M. A. (1992). The Social Psychology of Group Cohesiveness: From Attraction to Social Identity.

Hornaday, R. W. (2014). Sex composition, cohesion, consensus, potency and performance of simulation teams. Developments in Business Simulation and Experiential Learning, 28.

Langfred, C. W. (2000). The paradox of self-management: Individual and group autonomy in work groups. $\begin{array}{lllll}\text { Journal of } & \text { Brganizational }\end{array}$ http://dx.doi.org/10.1002/1099-1379(200008)21:5\%3C563::AID-JOB31\%3E3.0.CO;2-H

Levine, J. M., \& Moreland. (1990). Progress in small group research. Annual Review of Psychology, 41, 585-634 http://dx.doi.org/10.1146/annurev.psych.41.1.585 
Lewin, K. (1935). A dynamic theory of personality. New York: McGraw-Hill. http://dx.doi.org/10.1097/00005053-193611000-00051

Lott, A. J., \& Lott, B. E. (1965). Group cohesiveness as interpersonal attraction: A review of relationships with antecedents and consequent variables. Psychological Bulletin, 64, 269-309. http://dx.doi.org/10.1037/h0022386

Maslow, A. H. (1943). A theory of human motivation. Psychological Review, 50(4), 370. http://dx.doi.org/10.1037/h0054346

McClelland, D. (1961). The Achieving Society. New York: Free Press. http://dx.doi.org/10.1037/14359-000

McLeod, J., \& Von Treuer, K. (2013). Towards a Cohesive Theory of Cohesion. International Journal of Business and Social Research, 3(12), 1-11.

Mudrack, P. E. (1989a). Defining group cohesiveness: A legacy of confusion? Small Group Behavior, 20, 37-49. http://dx.doi.org/10.1177/104649648902000103

Mudrack, P. E. (1989b). Group cohesiveness and productivity: A closer look. Human Relations, 42, 771-785. http://dx.doi.org/10.1177/001872678904200902

Mullen, B., \& Copper, C. (1994). The relation between group cohesiveness and performance: Integration. Psychological Bulletin, 115, 210-227. http://dx.doi.org/10.1037//0033-2909.115.2.210

Mulvey, P. W., \& Klein, H. J. (1998). The impact of perceived loafing and collective efficacy on group goal processes and group performance. Organizational Behavior and Human Decision Processes, 74(1), 62-87. http://dx.doi.org/10.1006/obhd.1998.2753

Pescosolido, A. T., \& Saavedra, R. (2012). Cohesion and Sports Teams A Review. Small Group Research, 43(6), 744-758. http://dx.doi.org/10.1177/1046496412465020

Ratner, K. G., Dotsch, R., Wigboldus, D. H., van Knippenberg, A., \& Amodio, D. M. (2014). Visualizing minimal ingroup and outgroup faces: Implications for impressions, attitudes, and behavior. Journal of Personality and Social Psychology, 106(6), 897. http://dx.doi.org/10.1037/a0036498

Rosh, L., Offermann, L. R., \& Van Diest, R. (2012). Too close for comfort? Distinguishing between team intimacy and team cohesion. Human Resource Management Review, 22(2), 116-127. http://dx.doi.org/10.1016/j.hrmr.2011.11.004

Shaw, M. E. (1981). Group Dynamics: The Psychology of Small Group Behavior (3rd ed.). Montreal, Quebec: McGraw-Hill.

Stogdill, R. M. (1972). Group productivity, drive, and cohesiveness. Organizational Behavior and Human Performance, 8, 26-43. http://dx.doi.org/10.1016/0030-5073(72)90035-9

Taylor, D. M., Doria, J., \& Tyler, J. K. (1983). Group performance and cohesiveness: An attribution analysis. Journal of Social Psychology, 119, 187-198. http://dx.doi.org/10.1080/00224545.1983.9922820

Widmeyer, W. N., Brawley, L. R., \& Carron, A. V. (1990). The effects of group size in sport. Journal of Sport and Exercise Psychology, 12(2), 177-190.

Wise, S. (2014). Can a team have too much cohesion? The dark side to network density. European Management Journal, 32(5), 703-711. http://dx.doi.org/10.1016/j.emj.2013.12.005

\section{Copyrights}

Copyright for this article is retained by the author(s), with first publication rights granted to the journal.

This is an open-access article distributed under the terms and conditions of the Creative Commons Attribution license (http://creativecommons.org/licenses/by/3.0/). 